\title{
Prevalence of Motorcycle Helmet Use in Kathmandu, Nepal: An Observational Study
}

\author{
Steven M. Thygerson ${ }^{1}$, Marion J. House ${ }^{1}$, Robbie Chaney $^{1}$, Seshananda Sanjel ${ }^{2}$ \\ ${ }^{1}$ Department of Public Health, Brigham Young University, Provo, UT 84602, USA \\ ${ }^{2}$ School of Medical Sciences, Kathmandu University, Dhulikhel, Kavre, Nepal \\ Correspondence: Steven M. Thygerson, Department of Public Health, Brigham Young University, Provo, UT. 84602. \\ USA. E-mail: steven.thygerson@byu.edu
}

Received: September 16, 2019

doi:10.11114/set.v7i1.4662
Accepted: November 5, 2019 Online Published: December 23, 2019

URL: https://doi.org/10.11114/set.v7i1.4662

\begin{abstract}
This study investigated the rate of helmet use among motorcycle drivers and passengers in Kathmandu, Nepal during the Fall of 2016, and compared helmet use rates based on highways, main roads and secondary roads in the city. The study design involved cross-sectional observations along roadways in Kathmandu, Nepal. The following variables were studied: helmet use, gender, age category (youth, adult, elder), and type of road (highway, main road, secondary road). Statistical analysis included general behavioral prevalence, relationship comparison via Fisher's Exact Test, and odds ratios. A total of 1878 observations were made at 14 locations in Kathmandu; $n=1321$ observations of motorcycle drivers and $n=557$ observations of motorcycle passengers. Nearly all drivers used helmets $(0.994$ [1313/1321]; 95\% CI: [0.988, 0.997]), whereas the vast majority of passengers did not wear helmets $(0.014$ [8/557]; 95\% CI: [0.004, 0.021]). Helmet use was significantly different between drivers and passengers $\left(\chi^{2}(1, \mathrm{~N}=1872)=1791.0, \mathrm{p}<0.001\right)$. Driver gender was significantly associated with helmet use in that female drivers were more likely to wear helmets compared to male drivers ( $\mathrm{p}$ less than 0.001, Fisher's Exact Test). While motorcycle driver helmet use is high, passenger helmet use rates are considerably lower in Kathmandu compared to other countries. The current helmet laws and the enforcement of such laws influence the high use of helmets on the streets of Kathmandu. There is a need to enhance current helmet laws to include helmet compliance among motorcycle passengers to see a reduction in traffic injuries and fatalities.
\end{abstract}

Keywords: helmets, motorcycle, Nepal, safety, urban, transportation

\section{Introduction}

Motorcycles are a major form of transportation throughout Asia because they are inexpensive to purchase and maintain and are widely accessible. These factors have led to sharp increases in registered motorcycles in Asian countries (Hung, Stephenson, \& Ivers, 2006). In 2013, there were 1,204,150 registered motorcycles in Nepal representing 77.9\% of all registered motor vehicles. This is up significantly from 150,185 in 2000 (VAT Management, 2013). While statistics for motorcycle injuries is not available in Nepal, total motor vehicle crash statistics are. In 2013, there were 1,545,988 registered vehicles in Nepal (population: 22 million). In that same year there were 13,582 motor vehicle crashes with 1,816 fatalities. The fatality rate for 2013 was 11.75 fatalities per 10,000 vehicles. This rate was lower than both 2011 and 2012 with fatality rates of 14.36 and 13.68, respectively. However, this rate is much lower than just 11 years ago when 2002 had a fatality rate of 24.23 fatalities per 10,000 vehicles (VAT Management, 2013). When compared to other Asian countries, Nepal has one of the highest motor vehicle fatality rates (MoPPaT Management, 2013). With increased motorcycle use, related injuries are on the rise. Specifically, traumatic brain injury (TBI) and other head injuries are the result of motorcycle crashes. Both drivers and passengers are at risk for these severe injuries. In Figure 1, observe that all motorcycle drivers are wearing helmets and all passengers are not wearing helmets. Also, observe the number and location of traffic police wearing blue shirts and white caps. 


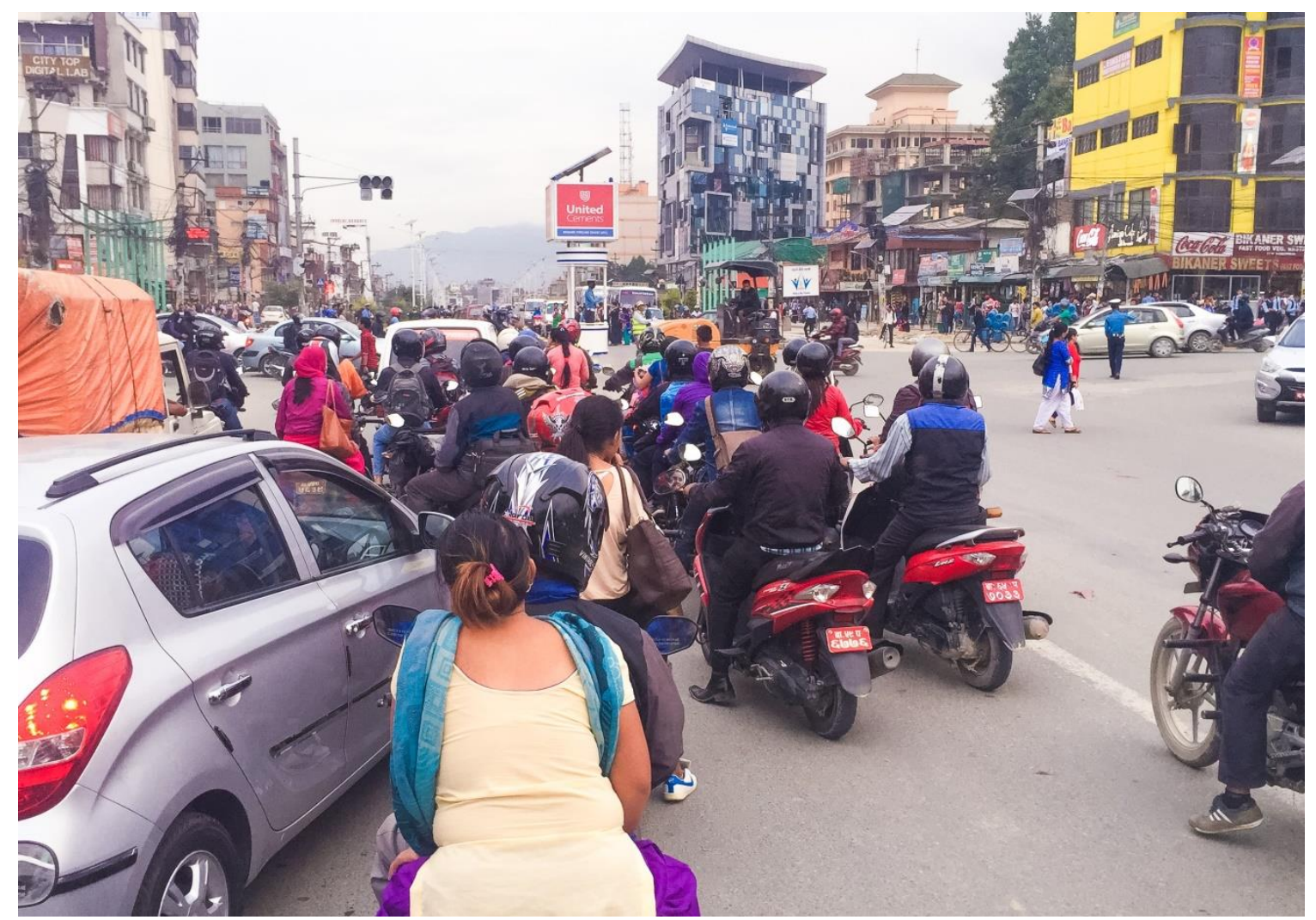

Figure 1. Helmet Use in Nepal; Photo by: Steven M. Thygerson

Motorcycle helmets are designed and highly recommended for use to protect against head injuries. There are several factors affecting motorcycle helmet use (Haqverdi, Seyedabrishami, \& Groeger, 2015; Hung, Stevenson, \& Ivers, 2008; Karuppanagounder, \& Vijayan, 2016; Mirkazemi \& Kar, 2014; Siddiqui et al., 2013; Sreedharan, Muttappillymyalil, Divakaran \& Haran, 2010; Thai, McIntosh, \& Pang, 2015). Several of these studies identify that helmet use laws and the strict enforcement of those laws are a major factor that increase helmet use among motorcycle drivers and passengers. Anecdotal observations on the main streets and highways of Kathmandu, Nepal reveal that motorcycle drivers are using helmets, however, passengers (including child passengers) are not. This is most likely due to the current regulation stipulating that all drivers must wear helmets while operating a motorcycle. This same law does not apply to any passengers, including children. Throughout the Kathmandu highways and main roads there is heavy traffic police presence. Along with directing traffic on the extremely busy roads, they also enforce traffic regulations by writing traffic citations. Minor traffic violations cost between 500 and 1500 rupees ( $\$ 5$ to $\$ 15$ USD) and increase for more serious violations. The fine for not wearing a helmet is 500 Nepali rupees $(\sim 5 \mathrm{USD})$. Police presence is much less on secondary roads that wind through neighborhoods. However, these poorly maintained roads are still used extensively as short cuts for taxis and others trying to avoid heavy traffic on the main roads, which increases the crash risk on these types of roads. There is no credible data on the prevalence of helmet use in Nepal. The main objective of this study is to estimate the prevalence of helmet use among motorcycle drivers and passengers in the Kathmandu metropolitan area of Nepal by comparing use rates among motorcycle drivers and passengers and the road type.

\section{Methods}

The study was conducted in Kathmandu, the capital and largest city of Nepal during the months of October and November 2016. The population of the city was estimated at 975,000 inhabitants based on latest census in 2012 (CBS, 2011). The large proportion of the population and business districts lie within the main highway of the city. This highway is known as 'Ring Road' as it encircles the entire city. To select observation sites, the city roads were divided into three road types based on a 1: 75000 road map. These divisions included highways, main roads and secondary roads. Four observation points were randomly selected from each type of road based on the nearest intersection, for a total of 14 observation sites. Observers were stationed approximately 100 meters from the selected intersection in order to observe moving motorcycles. At each point, observations were made for up to 30 minutes or 100 observations, whichever came first in order to avoid duplicate counts. Two observers were positioned at each point to simplify data collection, each observing a different flow of traffic using a standard observation field sheet. Two additional sites along 
the main highway in Dhulikhel, Nepal (approximately $20 \mathrm{~km}$ east of Kathmandu) were used to compare helmet use rates for areas outside the city. All observations were made during the daytime hours. The weather for each observation time was sunny and clear with an average daytime temperature of $24^{\circ} \mathrm{C}\left(75^{\circ} \mathrm{F}\right)$ for October and $23^{\circ} \mathrm{C}\left(73^{\circ} \mathrm{F}\right)$ for November. All roads were clear and dry.

Data for all drivers and passengers were collected for helmet use, estimated age category (youth, adult, elder), gender and type of road (highway, main road, secondary road). Age estimates were based on observation and experience only. Youth would be considered those of an age less than 12 and elder would be considered those over the age of 55 . Training and subsequent interrater agreement was conducted at one observation site along a main road in the city. Interrater agreement was $100 \%$ for all variables except age category. Age category agreement was above $95 \%$ for all observers.

Point prevalence was determined for driver and passenger helmet and mask use. Blaker's exact confidence intervals for a binomial proportion were computed for these prevalence values (Blaker, 2000). Categorical comparisons were using Fisher's Exact Test due to low cell counts (Routledge, 2005). Odds ratios were calculated to determine relationships between categorical variables. In cases where cell counts were zero, Haldane-Ascombe correction was used (Haldane, 1956; Anscombe, 1956). All data were analyzed using R statistical software, version 3.5.0 (R Development Core Team, 2018).

\section{Results}

A total of 1878 observations were made at 14 locations in Kathmandu; $n=1321$ observations of motorcycle drivers and $n=557$ observations of motorcycle passengers. Refer to Table 1 for descriptive statistics on driver demographics.

Table 1. Descriptive Statistics and Demographics of Drivers and Passengers

\begin{tabular}{rlll}
\hline & Male & Female & Total \\
\hline Drivers & 1226 & 94 & 1320 \\
\hline Passengers & 324 & 233 & 557 \\
\hline Helmet Worn & & & \\
$\quad$ As drivers & $1218 / 1226$ & $94 / 94$ & $1312 / 1321$ \\
$\quad$ As passengers & $4 / 324$ & $1 / 233$ & $5 / 557$ \\
$\quad$ Total & $1222 / 1550$ & $95 / 327$ & $1317 / 1878$ \\
\hline
\end{tabular}

Observations were made over the course of one week, starting on October 25, 2016 between 11:00 and 16:00, at highway $(n=550)$, main road $(n=371)$, and secondary road $(n=400)$ settings. $7.12 \%$ of drivers were female $(94 / 1320)$, whereas nearly half of the passengers were female (41.8\% [233/557]). Ages for drivers and passengers were both predominately adult-aged (97.2\% [1284/1321] and 81.5\% [454/557] respectively).

\subsection{Prevalence of Helmet by Drivers and Passengers}

Nearly all drivers used helmets (0.994 [1313/1321]; 95\% CI: [0.988, 0.997]), whereas the vast majority of passengers did not wear helmets $(0.014$ [8/557]; 95\% CI: [0.004, 0.021]). Helmet use was significantly different between drivers and passengers $\left(\chi^{2}(1, \mathrm{~N}=1872)=1791.0, \mathrm{p}<0.001\right)$.

\subsection{Road Types and Other Relationships}

There was a significant relationship between road type and driver helmet use ( $\mathrm{p}=0.04$, Fisher's Exact Test) in that drivers were much less likely to wear helmets while driving on highway roads (OR=9.93, $\mathrm{p}=0.01$; 95\% CI: [1.21, 80.91]). Driver gender was significantly associated with helmet use in that female drivers were more likely to wear helmets compared to male drivers ( $\mathrm{p}<0.001$, Fisher's Exact Test). Full results are presented in Table 2.

Table 2. Table of Relationships of Helmet Use by Driver, Passenger, and Road Characteristics

\begin{tabular}{lllllll}
\hline & Road Type & Driver Gender & Driver Age & Passenger Gender & Passenger Age \\
\hline Driver & $p=0.04$, Fisher's & $\mathrm{p}<0.001$, & $\mathrm{P}=0.116, \quad$ Fisher's & $\mathrm{p}=0.37, \quad$ Fisher's & $\mathrm{p}=0.48, \quad$ Fisher's \\
Helmet & Exact Test & Fisher's Exact & Exact Test & Exact Test & Exact Test \\
Use & & Test & & & \\
\hline Passenger & $p=0.147$, Fisher's & $\mathrm{p}=0.93$, Fisher's & $\mathrm{p}=1$, Fisher's Exact & $\mathrm{p}=0.41, \quad$ Fisher's & $\mathrm{p}=0.51, \quad$ Fisher's \\
Helmet & Exact Test & Exact Test & Test & Exact Test & Exact Test \\
Use & & & & & \\
\hline
\end{tabular}




\section{Discussion}

The results of this study show that helmet use is high among motorcycle drivers (99.4\%) yet very low among passengers (1.4\%). Use rates in Kathmandu are much higher for drivers compared to other studies observing helmet use rates throughout the world. Data for helmet use is limited but studies from Argentina, Mexico, and Vietnam were selected due to available studies and similar country development according to the United Nations' classification. Studies in Argentina and Mexico reported driver helmet compliance respectively at $69.8 \%$ and $76.3 \%$, which has been accredited to policies and efforts to promote helmet use (Ledesma, Lopez, Tosi, Poo, 2015; Lunnen et al., 2015). Conversely, passenger helmet use rates are considerably lower in Kathmandu compared to other countries. In Argentina, 43.4\% of passengers wear helmets and in Mexico, 51.6\% of passengers wear helmets (Ledesma et al, 2015). Mexico attributes a higher percentage of passenger helmet use to legislation being enforced among all motorcycle users (Lunnen et al., 2015). The gap between driver and passenger helmet use in Kathmandu is significantly wider than other country comparisons.

Current helmet legislation in Nepal calls for mandatory use of helmets for all motorcycle drivers but there are no enforceable provisions for passenger and child helmet use. Police enforcement for helmet use among drivers is high given that vehicle speeds throughout Nepal are generally low, making it much easier to identify and fine the offender, subsequently upholding legislative enforcement. Additionally, the prevalence of police at intersections and along most major roadways makes it difficult for motorcycle drivers to pass unnoticed without wearing a helmet. Any difference in the helmet use based on the type of roadway may be explained by lower police enforcement on secondary roads within the city.

An unexpected finding was significantly lower driver helmet use on highways when compared to main roads and secondary roads. Due to the sheer volume of both motor vehicle and pedestrian traffic, highways speeds are lower (maximum of 60 to 80 kilometers per hour) but experience constant heavy traffic, especially in Kathmandu, where the average speed is usually much lower. This increase in traffic volume requires greater police presence. Although, there is a higher police prevalence, one explanation of fewer observed drivers wearing helmets is that the police stationed at highway locations are focused on traffic control and less on helmet use and speeding enforcement. Conversely, the difference is still only slight when comparing helmet use based on roadway type.

An association of gender and helmet use was observed. Results show that female drivers are more likely to wear helmets. Similar findings were found in Argentina but not in Vietnam and Mexico where studies recorded male drivers being more likely to wear helmets. Nepal and Argentina may have cultural or social factors that create obstacles for the observed decrease use of helmets among males.

The high use of helmets on the streets of Kathmandu is influenced by the current helmet laws and the enforcement of such laws. However, helmet use is only prevalent among drivers and not passengers. As in other countries, increasing helmet use legislation enforcement increases helmet use. For example, Vietnam has worked on improving helmet use through legislation coupled with police enforcement and fines. Since 2007 when the country began implementing widespread helmet use initiatives, the country has seen a significant increase in helmet compliance. From studies conducted in 2011 and 2014, the region of Ha Nam has gone from 34.3\% to 76.9\% helmet use (Bao et al., 2017).

Limitations of this study include: the generalizability of data to specific dates and times along Kathmandu roads; large numbers of motorcycles passing by at any given time, making it nearly impossible to observe all motorcycles, and the difficulty in determining driver and passenger age.

\section{Conclusion}

There is a need to enhance current helmet laws to include helmet compliance among motorcycle passengers to see a reduction in traffic injuries and fatalities. Following the United Nations Motorcycle Helmet Study as a guide, other recommendations include: public awareness campaigns, and better access to helmets. Public awareness campaigns focusing on the importance of passenger and child helmet use, and the proper use of helmets will be helpful to educate the population. This can be promoted through health and transport divisions to show the benefits of helmet use for all motorcycle riders. Subsidies should also be provided to make helmets more affordable. Regulating the mandatory selling of helmets along with the motorcycle and subsidizing the cost of helmets will help to increase the availability of helmets among the population, especially passengers (United Nations Economic Commission for Europe, 2016). Additional engineering interventions should be studied that can either increase the use of motorcycle helmets or decrease the injury severity of motorcycle crashes. 


\section{References}

Anscombe, F. J. (1956). On estimating binomial response relations. Biometrika, 43(3/4), 461-464. https://doi.org/10.1093/biomet/43.3-4.461

Bao, J., Bachani, A. M., Viet, C. P., Quang, L., Nguyen, N., \& Hyder, A. A. (2017). Trends in motorcycle helmet use in Vietnam: results from a four-year study. Elsevier, 144, S39-44. https://doi.org/10.1016/j.puhe.2017.01.010

Blaker, H. (2000). Confidence curves and improved exact confidence intervals for discrete distributions. Canadian $J$ Stat., 28(4), 783-798. https://doi.org/10.2307/3315916

CBS. National Population Census 2011. (2012). Thapathali, Kathmandu, Nepal. Retrieved from http://cbs.gov.np/image/data/Population/Ward\%20Level/27Kathmandu_WardLevel.pdf

Haldane, B. J. (1956). The estimation and significance of the logarithm of a ratio of frequencies. Ann Human Genetics, 20(4), 309-311. https://doi.org/10.1111/j.1469-1809.1955.tb01285.x

Haqverdi, M. Q., Seyedabrishami, S., \& Groeger, J. A. (2015). Identifying psychological and socio-economic factors affecting motorcycle helmet use. Accid. Anal. Prev., 85, 102-110. https://doi.org/10.1016/j.aap.2015.09.007

Hung, D. V., Stevenson, M. R., \& Ivers, R. Q. (2006). Prevalence of helmet use among motorcycle riders in Vietnam. Inj Prev, 12(6), 409-413. https://doi.org/10.1136/ip.2006.012724

Hung, D. V., Stevenson, M. R., \& Ivers, R. Q. (2008). Barriers to, and factors associated, with observed motorcycle helmet use in Vietnam. Accid Anal Prev, 40(4), 1627-1633. https://doi.org/10.1016/j.aap.2008.05.002

Karuppanagounder, K., \& Vijayan, A. V. (2016). Motorcycle helmet use in Calicut, India: User behaviors, attitudes, and perceptions. Traffic Inj. Prev., 17(3), 292-296. https://doi.org/10.1080/15389588.2015.1055736

Ledesma, R., López, S., Tosi, J., \& Poó, F. (2015). Motorcycle helmet use in Mar del Plata, Argentina: prevalence and associated factors. Inter J Inj Contr Saf Promot., 22(2), 172-176. https://doi.org/10.1080/17457300.2013.877937

Lunnen, J., Pérez-Núñez, R., Hidalgo-Solórzano, E., et al. (2015). The prevalence of motorcycle helmet use from serial observations in three Mexican cities. Int J Inj Contr Saf Promot., 22(4), 368-376. https://doi.org/10.1080/17457300.2014.939195

Mirkazemi, R., \& Kar, A. (2014). Socio-economic determinants of helmet-wearing behaviour in Pune city, India. Int J Inj Contr Saf Promot, 21(4), 376-381. https://doi.org/10.1080/17457300.2013.838271

MoPPaT Management. (2013). Nepal road safety action plan - 2013-2020. Kathmandu, Nepal.

R Development Core Team. (2018). R: A Language and Environment for Statistical Computing (Version 3.5.0). https://cran.r-project.org/

Routledge, R. (2005). Fisher's exact test. Wiley Encyclopedia of Clinical Trials. https://doi.org/10.1002/0470011815.b2a10020

Siddiqui, S., Arora, S., Peipertm J., et al. (2013). Survey of helmet influences of female pillions in New Delhi. J. Surg. Res., 184(1), 404-410. https://doi.org/10.1016/j.jss.2013.05.103

Sreedharan, J., Muttappillymyalil, J., Divakaran, B., \& Haran, J. C. (2010). Determinants of safety helmet use among motorcyclists in Kerala, India. J Inj Violence Res, 2(1), 49-54. https://doi.org/10.5249/jivr.v2i1.26

Thai, K. T., McIntosh, A. S., \& Pang, T. Y. (2015). Factors Affecting Motorcycle Helmet Use: Size Selection, Stability, and Position. Traffic Inj. Prev., 16(3), 276-282. https://doi.org/10.1080/15389588.2014.934366

United Nations Economic Commission for Europe. (2016). The United Nations Motorcycle Helmet Study. How it works and how to join it series, WP.29. Retrieved November 2018 from https://www.unece.org/fileadmin/DAM/trans/publications/WP29/United_Nations_Motorcycle_Helmet_Study.pdf.

VAT Management. (2013). Status paper on road safety in Nepal, Kathmandu, Nepal.

\section{Copyrights}

Copyright for this article is retained by the author(s), with first publication rights granted to the journal.

This is an open-access article distributed under the terms and conditions of the Creative Commons Attribution license which permits unrestricted use, distribution, and reproduction in any medium, provided the original work is properly cited. 